1 Fundação Oswaldo Cruz (Fiocruz), Escola Nacional de Saúde Pública Sergio Arouca (Ensp) Departamento de Ciências Sociais (DCS) - Rio de Janeiro (RJ), Brasil. anacris.sousa@ensp.fiocruz. br

2 Instituto Federal de Educação, Ciência e Tecnologia do Rio de Janeiro (IFRJ) - Rio de Janeiro (RJ), Brasil.

\section{Desafios para o investimento público em saneamento no Brasil}

\author{
Challenges for public investment in sanitation in Brazil
}

Ana Cristina Augusto de Sousa $\mathbf{1 , 2}$, Joyker Peçanha Gomes ${ }^{\mathbf{1}}$

DOI: 10.1590/0103-11042019S703

RESUMO Este estudo investiga o desempenho dos principais programas de investimento em saneamento no âmbito do Programa de Aceleração do Crescimento (PAC) para mostrar se a escassez de recursos é o que explica o fracasso dessa política no País, como sustentam as atuais propostas de reforma do setor em tramitação. A partir dos dados sistematizados no Siga-Brasil e da análise dos relatórios dos órgãos de controle, foi possível reconstituir a trajetória de execução orçamentária dos programas e identificar as principais dificuldades enfrentadas para a sua operacionalização. À luz da literatura disponível, percebe-se que a estratégia federal centrada no incentivo financeiro reduziu o protagonismo da União ao repasse de verbas, quando era necessária uma atuação mais incisiva quanto aos problemas estruturais apresentados por municípios e estados brasileiros. Nesse sentido, o baixo gasto orçamentário estaria menos ligado à disponibilidade dos recursos que aos obstáculos institucionais encontrados em nível local, onde a política de saneamento é primariamente executada. Por fim, alerta-se para a necessidade de pensar arranjos de colaboração federativa mais eficazes em reduzir os custos transacionais de implementação dessa política, especialmente agora em que os cortes de orçamento ameaçam o fluxo de investimentos no setor.

PALAVRAS-CHAVE Política de saneamento. Saneamento básico. Saneamento urbano.

ABSTRACT This paper focus on the performance of the main programs of investment in sanitation within the scope of the GAP (Growth Acceleration Program - PAC) to show if scarcity of resources itself can explain the failure of such policy in the country, as supported by the current proposals to change regulation. Based on the data available in the Siga-Brasil database, and in the reports made by the existing accountability institutions, we were able to track the expenses of the projects and identifying the main difficulties which prevented them from succeeding. Based on the literature available, we could infer that the federal strategy focused mainly on financial incentive reduced the Union's role as an agent of transferring of funds, instead of acting on the main structural problems of the sector, found in Brazilian municipalities and states. In that sense, it concludes that underfunding would not have been the cause, but rather a reflection of the obstacles faced by the Union's strategy at the local levels, in which this policy is actually implemented. Finally, it recommends that we should think about new arrangements to reduce the transactional costs of the policy, especially now that cuts on public budget have interrupted the flow of investments to the sector.

KEYWORDS Sanitation policy. Sanitation programs. Urban sanitation. 


\section{Introdução}

Em 2007, em meio a um cenário marcado por baixos investimentos em infraestrutura, o Programa de Aceleração do Crescimento (PAC) propôs ampliar os investimentos públicos naárea, tornando-se a principal fonte de financiamento das obras de saneamento em todo o País. O Brasil contava então com quase metade de sua população sem esgotamento e praticamente um quinto dela sem acesso à água tratada 1 . O deficit de acesso atingia as populações mais pobres, concentradas nas regiões Norte e Nordeste e nas periferias das grandes cidades do território brasileiro.

De 2007 a 2018, o governo federal autorizou aproximadamente $\mathrm{R} \$ 34$ bilhões do orçamento fiscal e da seguridade social para ações de saneamento, visando alavancar a cobertura. O PAC foi o maior programa de investimentos no setor desde o fim do Plano Nacional de Saneamento (Planasa), em 1991. Ele disponibilizou recursos para obras de saneamento em cidades pequenas, médias e grandes de todo o País, sob supervisão de diferentes ministérios. Ainda assim, tímidos foram os resultados alcançados: com uma média de execução orçamentária em torno de $20 \%$, a cobertura de água avançou menos de $5 \%$ (de $80,9 \%$ a $83,5 \%$ ); e a de esgotamento, apenas $10 \%$ (de $42 \%$ a $52 \%$ ) até 20171 . Isso representa quase 20 milhões de brasileiros sem acesso à água e mais de 100 milhões sem esgotamento, além de um número considerável de obras por concluir.

O financiamento do setor sempre foi um ponto crítico para a literatura que investiga o desempenho da política de saneamento no Brasil. Recentemente, o governo federal vem recorrendo à crise econômica para justificar a interrupção do fluxo de investimentos públicos para o setor. Isso tem servido de base para iniciativas que propõem a sua abertura para o mercado. $\mathrm{O}$ entendimento do governo é que, somente com a participação dos grupos privados, o setor poderá ser provido dos recursos necessários para financiar a universalização do acesso. Nessa perspectiva, pouco se fala sobre os demais fatores que interferem no desempenho dessa política no País e que não necessariamente dependem dos recursos ou da natureza jurídica dos prestadores; menos ainda dos riscos que envolvem a opção pela privatização.

Para preencher essa lacuna, este trabalho investiga os principais fatores que atuaram decisivamente na performance do maior programa de saneamento urbano do Brasil e verifica se o subfinanciamento teria sido, de fato, causa ou reflexo de outros obstáculos e/ou estratégia adotada, no contexto da trajetória e da configuração federativa da operação desses serviços no País.

\section{Material e métodos}

As informações sobre as despesas do PAC no setor de saneamento tiveram como fontes o Sistema Integrado de Administração Financeira (Siafi) e o Sistema de Elaboração das Leis Orçamentarias (Selor), coletadas pelo Sistema de Informações sobre o Orçamento Público Federal (Siga-Brasil), de acesso público, o qual sistematiza o Orçamento Geral da União/Orçamento Fiscal e da Seguridade Social (OGU/OFSS), de natureza não onerosa ${ }^{2}$ (conhecida como fundo perdido por não gerar ônus ou encargos financeiros para o lado tomador/executor). $\mathrm{O}$ investimento não oneroso proporciona recursos para setores que não dispõem de repasses financeiros obrigatórios e serve também para induzir a adesão dos entes subnacionais aos programas federais e políticas nacionais que dependem da colaboração federativa, como as do setor de saneamento.

A partir das bases/universos 'LOA-20XX - Despesa Execução’ extraídas do Siga-Brasil e tratadas no Excel $^{\circledR}$ por ano (2007-2018), buscaram-se textos e códigos contidos nas variáveis para identificar aqueles que vinculavam as despesas ao PAC, segundo os filtros do Siga-Brasil, nos Manuais Técnicos de Orçamento ${ }^{3-6}$ e nas Atas publicadas no Portal do PAC 6 . Para o período de 2007-2010, eles foram identificados na variável 'Programas Selecionados (Cod/Desc)' pelos códigos 'l' e '2'; nas 'PI (Cod)' e 'PI (Objetivo)', referentes aos 
programas internos (2007-2018), pelos textos e códigos dos empreendimentos; e nas 'RP Siafi (Cod/Desc)' para 2011-2012 e 'Resultado EOF (Cod/Desc)' para 2013-2018 pelos códigos 3 e 5 (classificação das despesas por identificador de Resultado Primário). Em seguida, identificaram-se as despesas relacionadas com a subfunção orçamentária 512 (saneamento básico urbano), vinculadas ao Ministério das Cidades (MCid) e executadas nos Programas Orçamentários 0122 (Serviços Urbanos de Água e Esgoto) e 2068 (Saneamento Básico).

Dos R \$ 34 bilhões autorizados em programas e ações de saneamento inscritos sob o PAC entre 2007 e 2018, o MCid respondeu por R\$23,2 bi. Mais da metade deles ( $\mathrm{R} \$ 13,4 \mathrm{bi})$ foram destinados aos programas 0122 (Serviços Urbanos de Água e Esgoto) e 2068 (Saneamento Básico) em ações específicas de expansão da rede de água e esgotos. Dada a relevância no orçamento desse ministério, eles foram escolhidos como objetos deste estudo. Como a hipótese de que o subfinanciamento dos serviços foi um reflexo dos problemas de operacionalização das obras contratadas, a análise se concentrou no período pré-crise econômica, ou seja, Planos Plurianuais (PPAs) 2008-2011 e 2012-2015, época em que a farta disponibilização dos recursos permitiu evidenciar os reais motivos para as irregularidades (paralisia e atrasos) apresentadas pelas obras contratadas pelo programa.

Quanto à execução física, as informações sobre os empreendimentos contratados com recursos dos dois programas orçamentários foram fornecidas pelo $\mathrm{MCid}$, em resposta à solicitação baseada na Lei de Acesso à Informação, por meio de tabelas datadas de 2011 (0122) e 2015 (0122 e 2068).

Após tratamento e análise do conjunto do material coletado via Siga-Brasil e MCid, foi possível identificar os programas envolvidos (ano, código e nome das ações), calcular os valores empregados por etapas orçamentárias (dotação inicial prevista, dotação atualizada, empenho, liquidação e pagamento) e verificar a situação dos empreendimentos contratados durante os PPAs 2008-2011 e 2012-2015 (atrasados, paralisados, não iniciados, em andamento, concluídos).

O entendimento pleno dos efeitos da operacionalização dos empreendimentos sobre o fluxo orçamentário é demonstrado por material adicional obtido nos órgãos de controle interno (Controladoria Geral da União - CGU) e externo (Tribunal de Contas da União - TCU) da União, encarregados de auditar e julgar, respectivamente, o desempenho dos órgãos que administram os recursos federais. Nos relatórios de auditorias realizadas pela CGU e nos acórdãos do TCU, os principais dilemas experimentados pelos gestores se tornaram visíveis e permitiram formular a narrativa que orienta este texto. Técnicos da burocracia federal encarregados de gerir os contratos também foram consultados com o objetivo de esclarecimento de dúvidas pontuais a respeito do tema. Outras entidades significativas do setor, que reúnem os principais prestadores envolvidos na execução do programa, por sua vez, também foram procuradas (Associação de Empresas de Saneamento Básico Estaduais Aesbe - e Associação de Serviços Municipais de Água e Esgoto - Assemae), via e-mail e telefone, sem sucesso.

Os resultados apresentados a seguir representam um rápido retrato do programa e dos dilemas por ele enfrentados em nível nacional. É, portanto, um estudo de escopo geral e abrangente, que busca identificar condicionantes estruturais que afetaram a performance dos programas, marcados pela baixa execução financeira e física das obras em todas as regiões do País. Casos de sucesso não foram contemplados nesta análise, por motivos de método e fontes, basicamente: eles não são alvo dos órgãos de controle existentes, que enfatizam a fiscalização de irregularidades e pressuporiam estudos de caso.

\section{Resultados encontrados}

Os programas que responderam pelo empenho da maior parte dos recursos destinados à expansão urbana dos serviços de água e esgoto no MCid foram o 0122 (Serviços urbanos de água e 
esgoto, PPA 2008-2011) e o 2068 (Saneamento Básico, PPA 2012-2015). Juntos, eles responderam por R \$ 9,8 bilhões até 2015, em empreendimentos que beneficiaram municípios com mais de 50 mil habitantes ou integrantes de Regiões Metropolitanas, Regiões Integradas de Desenvolvimento Econômico ou de Consórcios Públicos com mais de 150 mil habitantes ${ }^{7}$.

A arquitetura básica do programa pressupunha que os entes federados (estados e municípios) concorressem aos recursos por meio da submissão de projetos ao ministério gestor. Após a seleção, seriam firmados os chamados termos de compromisso, por meio dos quais as transferências seriam autorizadas para os entes federados. Esses instrumentos eram administrados pelo próprio órgão repassador dos recursos federais ou pela Caixa Econômica Federal que, na qualidade de mandatária da União, repassaria os valores para os entes federados, monitorando e fiscalizando todos os procedimentos envolvidos na contratação e execução das propostas. Os entes federados, na qualidade de contratantes, estariam encarregados de atender à contrapartida acordada, se houvesse, e de providenciar toda a documentação e procedimentos necessários à viabilização dos empreendimentos ${ }^{8}$. Em outras palavras, os Governos Estaduais e Municipais, diretamente ou por intermédio de suas autarquias e empresas públicas, assumiriam a responsabilidade pelas atividades necessárias à execução dos empreendimentos. O fluxo dos repasses foi preservado de excepcionalidades pela conversão da natureza das transferências de voluntárias para obrigatórias e poupado de todas as dificuldades usuais que tornam irregular e imprevisível o repasse de recursos financeiros ${ }^{9}$. Os recursos eram depositados à frente da execução na conta corrente vinculada ao empreendimento, mas só podiam ser sacados após comprovada a execução na forma pactuada e com os requisitos técnicos e legais exigíveis.

Ao fim de uma década, no entanto, apenas em torno de $20 \%$ dos recursos empenhados, em média, foram efetivamente liquidados (isto é, efetivamente gastos) nos respectivos exercícios em que haviam sido assumidos (gráfico 1). Essa tendência caracterizou a execução orçamentária dos PPAs de 2008-2011, 20122015 e, em curso, 2016-2019.

Gráfico 1. Valor real e percentual de liquidação do valor empenhado nos Programas 0122 e 2068 sob a gestão do Ministério das Cidades. Brasil, 2008-2015

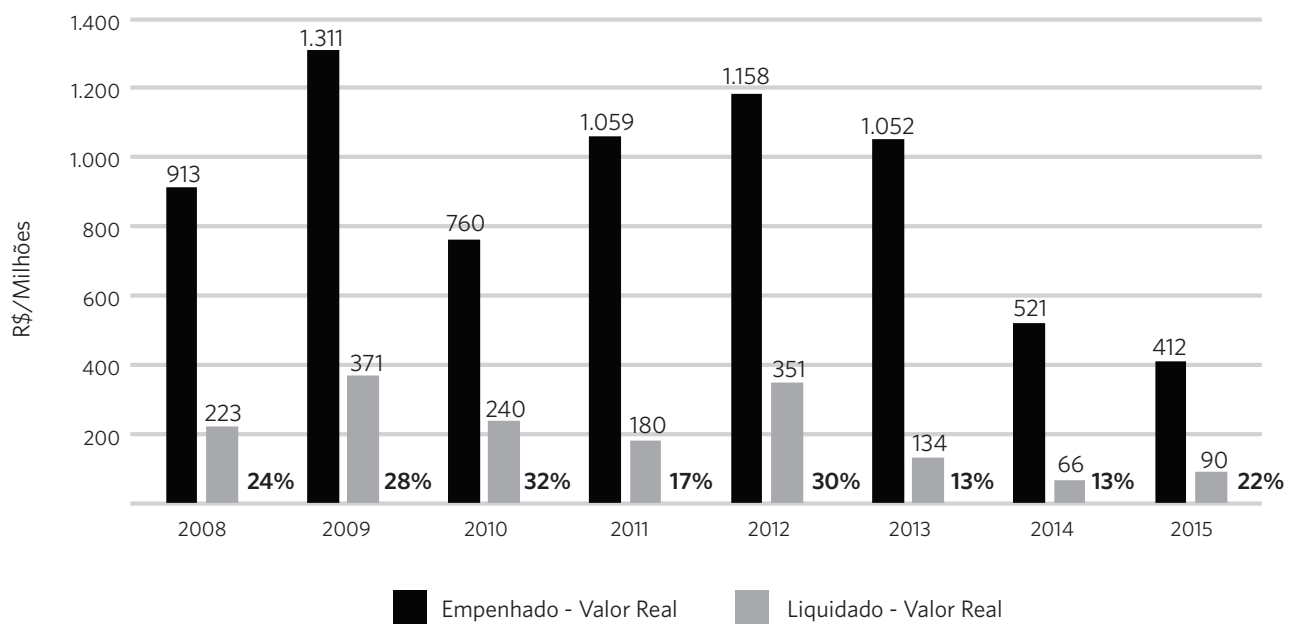

Fonte: Elaboração própria com base nos dados do Siafi e do Selor obtidos pelo Siga-Brasil.

Nota: Valores deflacionados pelo INCC-DI FGV, com apuração de junho de cada ano em relação a junho de 2008. Datas de atualização dos dados orçamentários utilizados por exercício, 2008 (31/12/2009), 2009 (31/12/2010) e 2010-2015 foram os últimos dias dentro do próprio exercício orçamentário. 
A baixa liquidação sinalizou que os recursos disponíveis não estavam sendo devidamente aproveitados. $\mathrm{O}$ monitoramento das obras mostrou que elas realmente não saíam do papel: levavam, em média, dois anos para iniciar-se e depois, paralisavam ou atrasavam. Para se ter uma noção, os registros de fins de 2011 indicaram que praticamente $90 \%$ (210) das obras contratadas no âmbito do 0122 no PPA 2008-2011 não tinham sido sequer iniciadas $^{10}$. No período seguinte, enquanto as obras do 2068 reproduziam essa performance, as do 0122 passaram a atrasar"1 . O problema atingiu todo o País e revelou que apenas uma pequena proporção dos empreendimentos encontrava-se em situação regular (tabela 1).

Tabela 1. Situação dos empreendimentos do PAC-Saneamento - Ministério das Cidades - Programas 0122 e 2068. Brasil, 2008-2015

\begin{tabular}{lrrrr}
\hline Situação da Obra* & \multicolumn{2}{c}{ PPA (2008-2011) } & \multicolumn{2}{c}{ PPA (2012-2015) } \\
& Quant. $^{\star \star}$ & Percentual & Quant. $^{\star \star}$ & Percentual \\
\hline Não iniciada & 2 & $0,45 \%$ & 166 & $66,67 \%$ \\
Atrasada & 113 & $25,34 \%$ & 21 & $8,43 \%$ \\
Paralisada & 157 & $35,20 \%$ & 14 & $5,62 \%$ \\
Em Andamento & 80 & $17,94 \%$ & 48 & $19,28 \%$ \\
Concluída & 94 & $21,08 \%$ & 0 & $0,00 \%$ \\
Total & 446 & $100 \%$ & 249 & $100 \%$ \\
\hline
\end{tabular}

Fonte: Elaboração própria a partir de dados de acesso público enviados pelo Ministério das Cidades.

* Situação da obra atualizada em dezembro de 2015

** Quantidade de empreendimentos assinados nos respectivos períodos do PPA.

A baixa execução orçamentária indicou a presença de irregularidades que interferiam diretamente no repasse dos recursos previstos, como projetos e orçamentos de baixa qualidade técnica e flagrante descumprimento da documentação e dos prazos de execução pactuados no ato da contratação. Entre as causas de atraso ou suspensão temporária das obras mais frequentemente observadas nos relatórios das auditorias realizadas no órgão gestor dos programas, estiveram ${ }^{\mathbf{1 2}}$ :

1) Revisão necessária no projeto técnico de engenharia;

2) Inexistência de licenças ambientais prévias e atrasos na obtenção de licenças ambientais adicionais;
3) Obtenção de documentação comprobatória da titularidade da área em que a obra era realizada (problemas de invasão, imóveis irregulares à espera de remoção, área de proteção ambiental, entre outros);

4) Aporte de contrapartidas dos entes acordadas em contrato até 2011;

5) Atrasos e/ou irregularidades nos processos de licitação (desvios de verba, superfaturamento, aplicação de preços acima da mediana, existência de empresas fantasmas fornecedoras de bens e de serviços, descumprimentos das legislações trabalhistas, previdenciárias e tributárias, irregularidades ambientais e problemas nos projetos);

6) Falhas construtivas nas obras, baixa 
qualidade dos serviços e material empregados, na maioria das vezes em desacordo com o projeto aprovado;

7) Desarticulação entre as ações das esferas federal, estadual e municipal nos empreendimentos de maior porte: obras dependendo de infraestrutura a ser feita por outras secretarias de governo;

8) Rescisões contratuais com empreiteiras, que interrompem a execução das obras e geram novo processo administrativo de contratação;

9) Forte restrição de recursos em decorrência da crise econômica de 2016, que atrasou pagamentos e impediu novas contratações.

É possível perceber que os apontamentos da lista acima referiam-se essencialmente a competências atribuídas primariamente aos estados e municípios beneficiados pelos programas. O alto número de obras não iniciadas resultava da aplicação de cláusulas suspensivas emitidas pela Caixa, que administrava os contratos e monitorava os empreendimentos. Tais cláusulas eram aplicadas basicamente quando o projeto do empreendimento possuía falhas técnicas e/ou quando não apresentava licenças ambientais prévias e documentação comprobatória da titularidade da área em que a obra era realizada. A reapresentação do projeto exigia que os valores fossem atualizados; e a planilha orçamentária, readequada. O contrato era então reprogramado com o agente financiador, em nova repactuação de cronograma que contemplasse os processos licitatórios e a adequação de prazos. Esse processo consumia tempo, gerando atrasos e paralisias nas obras.

A configuração originária dessa situação ocorreu no lançamento do programa, quando o MCid permitiu que os proponentes empenhassem recursos em contratos de obras que, na maioria dos casos, não tinham projeto de engenharia aprovado, orçamento detalhado, as necessárias licenças ambientais ou documentos de titularidade do terreno onde seriam executadas as obras públicas. Tal 'permissividade' expressou o senso de oportunidade do MCid na época, que preconizou o empenho - reivindicado historicamente - no setor em detrimento da burocracia, que julgava ser sanável13. Essa conduta promoveu a contratação em massa dos empreendimentos na expectativa de que os proponentes buscassem sanar as irregularidades. No entanto, isso não aconteceu; e, diante das dificuldades, muitos proponentes desistiram dos contratos.

Junto com a CGU, o TCU percebeu a estratégia do MCid e determinou que ele restringisse a utilização de cláusulas suspensivas nos contratos firmados de forma a evitar que os planos de trabalho constituíssem elementos meramente formais. Depois, orientou que ele exigisse do proponente, previamente à celebração dos contratos de repasse, a apresentação do projeto técnico da obra, do comprovante de titularidade da área de intervenção e das análise e aprovação prévias dos setores técnicos competentes ${ }^{14}$. Atendendo ainda às reiteradas recomendações da CGU ao longo de anos, o órgão enfatizou a necessidade de que ele instituísse um sistema de monitoramento próprio dos empreendimentos administrados pela Caixa, para assegurar um maior controle e engajamento com o desempenho das ações contratadas ${ }^{15}$.

Em resposta, o MCid apenas endureceu as regras na segunda fase de contratação. As contrapartidas exigidas até 2011 também constituíam um obstáculo considerável não apenas porque alguns estados e municípios tinham dificuldade de aportar os recursos, mas principalmente porque ocorria sobreposição das burocracias federal e estadual/municipal, o que duplicava o tempo necessário para aprovação de um projeto e para realização de cada pagamento durante a execução da obra. $\mathrm{O}$ aporte de recursos estaduais ou municipais demandava a sua inclusão na lei orçamentária e no PPA local, a necessidade de aprovar a licitação e o contrato, a análise técnica de cada entrega e sua aprovação pelo fiscal, pela autoridade da secretaria de obras e pela área 
orçamentária e financeira do estado/município, além da prestação de contas final e da atuação dos controles locais. A sua eliminação, em 2011, reduziu bastante a burocracia e a ineficiência do processo administrativo para o ciclo seguinte.

A emissão sistemática de cláusulas suspensivas que resguardavam o empenho e os inúmeros decretos e normativas que prorrogaram os prazos dos convenentes para o cumprimento dos requisitos não vieram acompanhados de uma intervenção tempestiva da União para a resolução das dificuldades que mais afetavam os convenentes, essencialmente resultantes de sua fragilidade técnica, gerencial e da desarticulação das instâncias envolvidas ${ }^{16-21}$. Embora o instrumento de planejamento local da expansão dos serviços de saneamento (plano de saneamento) fosse obrigatório por lei, apenas um terço dos municípios consultados pelo MCid dispunham dele em fins de $2016^{22}$. Nesse mesmo ano, a crise política e econômica que se fez sentir no País, a partir de 2015, chega ao extremo; e o orçamento autorizado para o PAC-Saneamento básico urbano alcançou seu nível mais baixo (gráfico 2):

Gráfico 2. Valor real do orçamento federal autorizado como PAC para investir em saneamento básico urbano (Subfunção 512). Brasil, 2007-2018

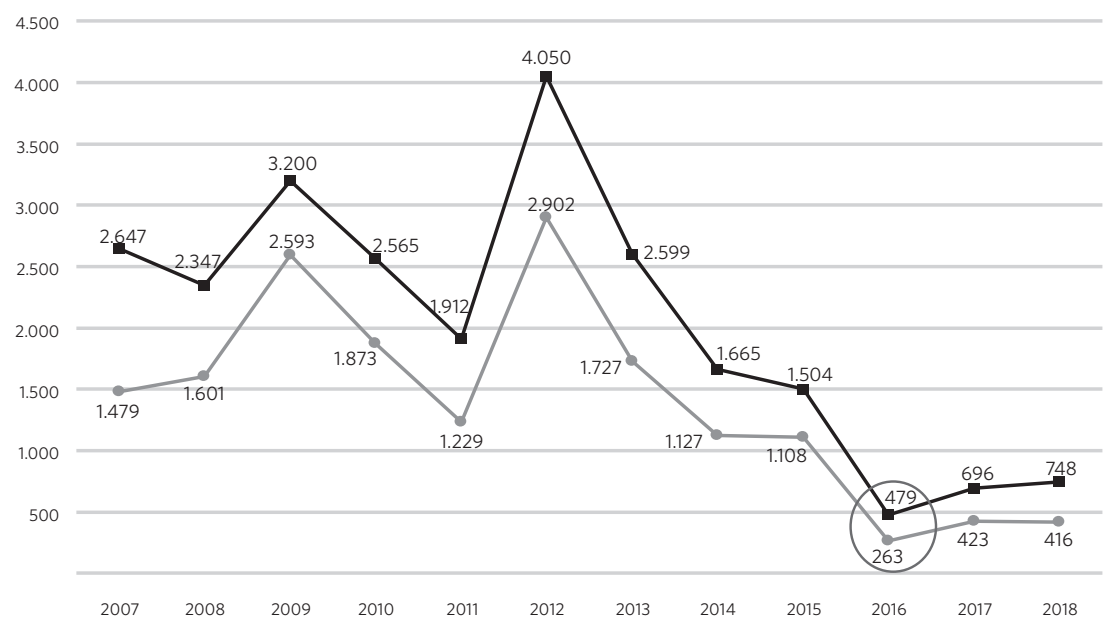

Fonte: Elaborado pelos autores com base nos dados do Siafi e do Selor obtidos pelo Siga-Brasil.

Nota: Valores deflacionados pelo INCC-DI FGV, com apuração de junho de cada ano em relação a junho de 2007.

Apesar do histórico de picos no orçamento federal autorizado com queda nos dois anos seguintes (período de execução do empenhado nos exercícios anteriores), observa-se uma interrupção da trajetória em 2015 que não foi retomada no PPA 2016-2019 (gráfico 2). Essa interrupção inviabilizou a aplicação da rotina de monitoramento prevista pela Secretaria Nacional de Saneamento Ambiental (SNSA), provocando atrasos de 120 dias no pagamento dos contratos, o que desmobilizou e reduziu mais ainda o ritmo de andamento das obras, com a suspensão de novos empreendimentos em 32 municípios e 15 estados, além do comprometimento das ações de planejamento e capacitação dos gestores ${ }^{23}$.

\section{Discussão de resultados}

O PAC foi um dos programas econômicos mais polêmicos adotados no Brasil. Ainda não há consenso na literatura sobre o significado dos seus efeitos. Enquanto alguns autores o 
percebem como mera reedição da cartilha do mercado, que favoreceu a integração periférica do País ao sistema econômico internacional, outros destacam os seus efeitos concretos sobre a redução interna da desigualdade, sobre a geração de emprego e sobre a distribuição de renda ${ }^{24}$. A adoção do PAC representou a vitória de setores desenvolvimentistas presentes na coalização governamental da época, que percebiam o Estado como principal indutor do desenvolvimento econômico e social do Brasil, na medida em que o incremento no nível de investimentos públicos elevaria a produtividade e a competividade dos agentes econômicos. Com a percepção de que o ajuste fiscal não provocara uma aceleração substancial na economia, tampouco proporcionara o esperado aumento de renda e geração de emprego, o papel da infraestrutura na agenda de investimentos do governo federal foi reabilitado por meio da formulação e implementação de um programa de crescimento econômico e de redução da desigualdade social no País como forma de alavancar o desenvolvimento ${ }^{25}$.

Até o PAC, boa parte da literatura sustentava que o fracasso da política de saneamento se devia ao subfinanciamento, em razão da adoção de uma perspectiva liberal por parte do governo federal nos anos $1990^{26}$. Todavia, depois do plano, essa tese perdeu a força para explicar os tímidos resultados alcançados. $\mathrm{O}$ setor de saneamento foi bastante beneficiado pelo programa, com significativo aporte de recursos associado a uma nova regulação que teria a função de dar segurança aos investimentos. No entanto, isso não foi suficiente para ultrapassar determinados obstáculos mais estruturais do setor no País, marcado pela baixa capacidade de gestão local sobre esses tipos de contrato e serviços.

Em que pesem as dificuldades e os equívocos cometidos pelo MCid, a pesquisa constatou que não foram eles que responderam primariamente pelo baixo desempenho verificado na execução dos empreendimentos. A tarefa de operacionalizá-los cabia aos municípios e aos estados. A baixa qualidade dos projetos apresentados, a ausência de planejamento e a negligência para com a documentação necessária mostraram que a maior parte dos governos estaduais e municipais não dispunha ainda de estrutura e instrumentos de gestão sólidos o bastante para gerir os contratos assumidos com a União. Esta, por sua vez, também não foi capaz de viabilizar ou de coordenar saídas para os dilemas enfrentados por eles. Muitos deles preferiram então abrir mão dos recursos disponibilizados a cumprir as condições colocadas para o seu acesso.

Nas regiões mais críticas do País, a baixa capacidade técnica para lidar com a burocracia necessária aos empreendimentos e a desarticulação intergovernamental se mostraram ainda mais dramáticas. A opção política da União de combater o deficit dos serviços, priorizando financiar as regiões mais deficitárias de acesso, não estimou devidamente o peso da fragilidade das estruturas institucionais locais existentes para a execução dos programas. O caso da região Norte foi o exemplo mais visível. Com o maior deficit de atendimento do Brasil, essa foi a região que menos investiu em saneamento no período ${ }^{27}$. Quando as regras enrijeceram, ela praticamente deixou de contratar os recursos disponibilizados, retroalimentando assim a sua já desvantajosa posição no cenário nacional. O desempenho frustrante das regiões Sul e Sudeste, de onde eram esperados melhores resultados, também sinalizou que a estratégia do governo de priorizar áreas com maior deficit pode ter provocado um efeito perverso não previsto: a seleção de candidatos inexperientes demais no setor. Essa hipótese precisaria ser devidamente investigada em estudos adicionais que se debruçassem sobre as particularidades regionais do desempenho do programa, o que infelizmente não integra o escopo da presente análise.

Segundo Arretche ${ }^{\mathbf{2 8}}$, o sucesso da implementação e do desempenho das políticas sociais seria determinado pelo grau da supervisão federal e de regulação da legislação envolvida. Ela mostra que nas políticas mais reguladas, como saúde e educação, cujos 
patamares mínimos de gasto e as modalidades de execução eram estipulados pela União, o gasto tendeu a ser priorizado nas subunidades da federação quando comparado com o gasto de políticas menos reguladas, como habitação e saneamento. Isso porque as obrigações impostas pela regulação federal (transferências regulares e patamares mínimos de gasto) limitavam a autonomia decisória local, obrigando os municípios a se envolverem nas políticas públicas e amarrando os gastos nos setores regulados.

Já nas políticas menos reguladas, que não dispunham de transferências regulares nem de patamares mínimos de gasto, a ausência de constrangimentos permitiu que o investimento de municípios e estados na provisão dos serviços envolvidos fosse relegado a segundo plano nas prioridades de gastos do governo. Isso explicaria boa parte do subfinanciamento crônico dessas políticas públicas e a desigualdade regional observada na provisão.

A política de saneamento não contou e ainda não conta com transferências obrigatórias ou universais, nem com patamares mínimos de gasto exigidos para os governos. A competência dela é comum a todos os níveis de governo, mas descentralizada em nível de execução. No atual arranjo federativo, políticas públicas que pressupõem o exercício de competência comum para serem implementadas, mas não são intensamente reguladas, dependem do comprometimento dos entes subnacionais para decolar. A adesão destes é obtida via oferta de incentivos que proporcionem a eles ganhos maiores do que perdas ${ }^{29}$. $\mathrm{O}$ incentivo financeiro é definitivamente um deles, mas, no caso do saneamento, ele se revelou, no desenho do programa, insuficiente para promover a adesão dos atores. O investimento no desenvolvimento de instituições que pudessem lidar com as condições exigidas para a contratação e o financiamento das obras mostraram-se mais custosos que as próprias obras em si. Por isso, muitos abandonaram a oportunidade.

A concentração histórica da estrutura institucional nas mãos dos estados, por meio das companhias estaduais de saneamento, conferiu aos governos subnacionais considerável autonomia decisória, o que deixou por muito tempo essa política aos caprichos das autoridades locais e dos incentivos financeiros federais. Sem constrangimentos de qualquer natureza, ela foi relegada na agenda de gastos de todos os níveis de governo. Nessa chave analítica, o equívoco dos programas de saneamento propostos pela União teria residido em superestimar o efeito do incentivo financeiro sobre os entes subnacionais, ignorando os altos custos envolvidos no aprimoramento de uma estrutura institucional afeita às políticas minimamente reguladas, que teria de ser integralmente assumido por eles, com uma boa dose de dedicação.

$\mathrm{O}$ atual estágio de investigação do objeto ainda não permite afirmações conclusivas, mas permite levantar algumas hipóteses a partir do diálogo com a literatura. Sousa e Costa $^{\text {30-32 }}$ explicariam que o alto custo associado ao desenvolvimento de uma estrutura setorial local teria resultado do legado histórico do setor de saneamento, segundo o qual a estrutura institucional setorial dos municípios teria sido atrofiada por décadas em favor da hegemonia da estrutura institucional mantida pelos estados. Entretanto, nas fontes consultadas, não houve menção ao desempenho supostamente superior de estados em relação a municípios ou mesmo à natureza jurídica ou administrativa dos operadores dos serviços. Esse aspecto é intrigante, dada a posição hegemônica conquistada pelas companhias estaduais no setor, consolidada, entre outros fatores, pela monopolização da expertise na área.

Embora operadores privados não tenham sido beneficiados pelo programa, não custa tecer alguns comentários sobre o tema, uma vez que ele sempre vem à tona quando se discute o setor no Brasil. Partidários da privatização alegam que empresas privadas teriam desempenho superior a empresas ou serviços estatais. Na verdade, nenhuma metodologia já aplicada para comparar o desempenho de diferentes prestadores de 
serviços de saneamento corroborou essa afirmação. Isso mostra que a questão ligada à natureza jurídica dos prestadores tem sido um fator bastante superestimado no debate público a respeito da performance dos serviços no País ${ }^{33}$. Em revisão de literatura sobre o assunto, Scriptore e Toneto $\mathrm{Jr}^{34}$ mostraram que, nas comparações analisadas, os resultados encontrados não suportam essa afirmação. Sarti e Ultramere ${ }^{35}$ mostram ainda que a abertura de capital de empresas de saneamento não produziu impactos substanciais na cobertura, pois a opção preferencial pela remuneração dos acionistas constrangeu as decisões de investimento na expansão dos serviços. Esses autores, em especial, alertam para os constrangimentos impostos à universalização quando empresas de água e esgoto se subordinam à lógica da financeirização e adotam mecanismos de governança mimetizados do setor privado.

Nas últimas duas décadas, a privatização dos serviços de água e esgoto tem sido progressivamente revertida nos principais países onde ela foi implantada ${ }^{36}$. Do ano 2000 até 2017, 267 cidades que privatizaram os seus sistemas optaram pela reestatização, incluindo Paris, Madrid e Berlim. A reversão foi impulsionada por um leque de problemas reincidentes, como serviços inflacionados, ineficientes e com investimentos insuficientes. As privatizações ou Parcerias Público-Privadas (PPP) acarretaram tarifas muito altas, não cumpriram promessas e operaram sem transparência, entre diversos outros problemas ${ }^{37}$.

Do mesmo modo, mas no sentido inverso, autores que atribuem o fracasso da política de saneamento às investidas da privatização ${ }^{\mathbf{3 8 , 3 9}}$ perdem de vista que, no Brasil, as empresas privadas nunca ultrapassaram $10 \%$ do mercado dos serviços'. Essa literatura, embora extremamente útil para mapear e compreender a atuação de grandes grupos econômicos da água e da construção civil sobre as decisões políticas no setor, não explica, infelizmente, a inoperância e os entraves de boa parte dos operadores públicos com relação aos programas e incentivos propostos especialmente para eles.

Os autores que levantaram, em estudos de caso, as dificuldades enfrentadas por municípios no planejamento dos serviços de saneamento sugeriram que a União investisse mais em ações de apoio aos gestores locais, com iniciativas específicas de assistência técnica, capacitação, entre outras medidas consideradas estruturantes do planejamento e da gestão municipal40,41. Embora esses estudos não permitam maiores generalizações, eles disponibilizaram materiais concretos de feedback para a avaliação das políticas propostas, com recomendações que acertaram no alvo: é preciso mirar nas instituições setoriais locais e seus gestores.

Ao que tudo indica, o maior obstáculo encontrado para viabilizar a operacionalização dos empreendimentos foi a fragilidade das estruturas e dos instrumentos de gestão setorial de boa parte dos governos estaduais e municipais envolvidos no programa e a própria falta de priorização política dos serviços pelos seus governantes. A combinação desses dois obstáculos tornou os custos de incentivo altíssimos tanto para a União como para os demais entes envolvidos. Agora, em função da restrição orçamentária ocorrida em 2016, com drástica redução das metas do PPA pelo Ministério do Planejamento, é possível que tais custos se tornem ainda mais elevados.

\section{Considerações finais}

Este estudo representou o primeiro passo para entender os desafios colocados para o desempenho dos programas de saneamento no País a partir da análise dos principais obstáculos experimentados pelo PAC Saneamento. Esperase que estudos futuros possam aprofundar a compreensão desses desafios, em análises que possam focalizar outros contextos e variáveis pertinentes que não foram abordados aqui, tais como a performance por regiões, o porte das obras e das cidades, bem como o volume financeiro dos contratos. 
*Orcid (Open Researcher and Contributor ID).

As evidências aqui apresentadas reforçam a visão de que o papel dos governos subnacionais no federalismo brasileiro é crucial para a implantação da agenda do governo federal na política de saneamento. Na ausência de transferências obrigatórias e de vinculação de gastos, as políticas públicas de saneamento não foram priorizadas pelos governos municipais brasileiros. Isso teria condicionado os gastos realizados nas últimas décadas e atrofiado a capacidade setorial das instituições locais para lidar com os procedimentos necessários à execução dos contratos. Ao que tudo indica, a fragilidade de governança setorial de boa parte dos governos estaduais e municipais, encarregados de empreender aos executores locais as obras contratadas, foi a maior dificuldade que a União se deparou para expandir os serviços de água e esgoto no País.

A estratégia centrada no incentivo financeiro como principal mecanismo de indução reduziu o protagonismo da União ao repasse de verbas e não atuou tempestivamente sobre problemas estruturais do setor, que exigiriam dela ter colaborado mais ativamente para a estruturação e profissionalização das estruturas setoriais estaduais e municipais de saneamento, encarregadas de implementar os programas propostos.

Infelizmente, a atual conjuntura e a consequente retomada do paradigma liberal para a provisão dos serviços públicos no Brasil têm reduzido todo o debate no setor à privatização dos prestadores, sem atentar para o fato de que uma estrutura mínima e eficaz de governança setorial precisa ser desenvolvida em todos os níveis da federação antes. Diante da experiência observada no mundo, a opção de privatizar parece ser a mais precipitada, e não a mais adequada para lidar com os desafios de uma política pública de natureza social que trata de um direito humano, como o acesso ao saneamento.

O número expressivo de entes beneficiados pelo programa que não dispuseram das condições mínimas para acessar os recursos disponibilizados levanta a necessidade de repensar novos arranjos de colaboração federativa que sejam mais eficazes em reduzir os custos da implementação para os entes envolvidos. $\mathrm{Na}$ conjuntura econômica atual, em que o corte de gastos públicos ameaça interromper o fluxo de investimentos no setor, o aprimoramento da capacidade de gestão dos governos e da respectiva estrutura estatal relativa ao setor é essencial para dar continuidade ao processo de universalização do saneamento no Brasil.

\section{Agradecimentos}

À Fundação de Amparo à Pesquisa do Estado do Rio de Janeiro (Faperj) pelo financiamento concedido à pesquisa e, em especial, à equipe técnica da SNSA do Ministério das Cidades e do Planejamento (MPOG).

\section{Colaboradores}

Sousa ACA (0000-0002-5288-2274)*: responsável pela concepção, delineamento, análise de dados, conclusões e redação final do texto. Gomes JP (0000-0001-8354-8677)*: contribuiu para a coleta, sistematização, tratamento e análise dos dados e conclusões do texto. 


\section{Referências}

1. Brasil. Ministério do Desenvolvimento Regional. Diagnóstico anual de Água e Esgotos [internet]. Sistema Nacional de Informações sobre Saneamento - SNIS. [acesso em 2019 mar 20]. Disponível em: https://t.ly/ XBoyb.

2. Brasil. Senado Federal. Siga-Brasil: Portal do Orçamento [internet]. Orçamento Federal. 19 Mar 2019 [acesso em 2019 mar 23]. Disponível em: https:// www12.senado.leg.br/orcamento/sigabrasil.

3. Brasil. Ministério do Planejamento, Orçamento e Gestão. Manual Técnico do Orçamento [internet]. Portal do Governo Brasileiro. 20 Mar 2019. [acesso em 2019 mar 20]. Disponível em: https://is.gd/cqncfY.

4. Brasil. Ministério do Planejamento, Orçamento e Gestão. Manual Técnico de Orçamento - MTO. Versão 2008-4 [internet]. Secretaria de Orçamento Federal; 2008. [acesso em 2019 mar 20]. Disponível em: https://is.gd/FIo7r9.

5. Brasil. Ministério do Planejamento, Orçamento e Gestão. Manual Técnico de Orçamento - MTO. Versão 2010-6 [internet]. Secretaria de Orçamento Federal; 2010. [acesso em 2019 mar 20]. Disponível em: https://is.gd/P5BEEn.

6. Brasil. Ministério do Planejamento, Orçamento e Gestão. Manual Técnico de Orçamento - MTO. Versão 2013 [internet]. Secretaria de Orçamento Federal; 2013. [acesso em 2019 mar 20]. Disponível em: https://is.gd/u76wld.

7. Brasil. Programa de Aceleração do Crescimento - PAC [internet]. PAC - Ministério do Planejamento. 17 Mar 2019. [acesso em 2019 mar 17]. Disponível em: http:// www.pac.gov.br/.

8. Brasil. Ministério das Cidades. Manual de Instruções para Aprovação e Execução dos Programas e Ações do Ministério das Cidades: Projetos inseridos no Programa de Aceleração do Crescimento - PAC [internet]. Ministério das Cidades; 26 Jun 2013. [acesso em 2017 jul 30]. Disponível em: https://is.gd/cGJafo.
9. Brasil. Lei no 11.578, de 26 de novembro de 2007. Dispõe sobre a transferência obrigatória de recursos financeiros para a execução pelos Estados, Distrito Federal e Municípios de ações do Programa de Aceleração do Crescimento - PAC, e sobre a forma de operacionalização do Programa de Subsídio à Habitação de Interesse Social - PSH nos exercícios de 2007 e 2008 [internet]. Diário Oficial da União; 27 Nov 2007. [acesso em 2017 jul 30]. Disponível em: http://www. planalto.gov.br/ccivil_03/_ato2007-2010/2007/Lei/ L11578.htm.

10. Brasil. Ministério das Cidades. Balanço Externo PAC - Dez/2011 [arquivo eletrônico - Base Balanço PAC 2011.xls]. Secretaria Nacional de Saneamento Ambiental. Departamento de Articulação Institucional. Coordenação-Geral de Informações, Estudos e Pesquisas; 11 Nov 2016.

11. Brasil. Ministério das Cidades. Balanço Externo PAC - Dez/2015 [arquivo eletrônico - Balanço PAC_ dez_2015.xlsx]. Secretaria Nacional de Saneamento Ambiental. Departamento de Articulação Institucional. Coordenação-Geral de Informações, Estudos e Pesquisas; 31 Out 2016.

12. Brasil. Auditorias Anuais de Contas [internet]. Controladoria-Geral da União. [acesso em 2019 fev 13]. Disponível em: https://t.ly/261.

13. Brasil. Tribunal de Contas da União, Aguiar U. Acórdão 347, de 14 de março de 2007. Relatório de Levantamento - Processo 017.387/2006-3 [internet]. TCU; 14 Mar 2007. [acesso em 2017 ago 13]. Disponível em: https://is.gd/NAXljW.

14. Brasil. Tribunal de Contas da União, Monteiro JM. Acórdão 2.824, de 25 de novembro de 2009. Relatório de Auditoria - Processo 026.670/2007-0 [internet]. TCU; 25 Nov 2009. [acesso em 2017 ago 13]. Disponível em: https://is.gd/1H5QYf.

15. Brasil. Tribunal de Contas da União, Carvalho A. Acórdão 3.180, de 07 de dezembro de 2016. Relatório de Auditoria - Processo 017.507/2015-4 [internet]. 
TCU; 12 Jul 2016. [acesso em 2019 jan 2]. Disponível em: https://is.gd/Oynljw.

16. Brasil. Ministério das Cidades. Portaria no 563, de 30 de dezembro de 2009. Prorrogar, até 31 de março de 2010, o prazo para atendimento das exigências técnicas previstas em cláusula suspensiva dos Termos de Compromisso firmados nos exercícios de 2007 e 2008, inseridos no Programa de Aceleração do Crescimento - PAC. [internet]. Diário Oficial da União; 31 Dez 2009. [acesso em 2017 ago 13]. p. 66. Disponível em: https://is.gd/sfSc8i.

17. Brasil. Ministério das Cidades. Portaria no 311, de 30 de junho de 2010. Prorrogar, até 12 de novembro de 2010, o prazo para atendimento das exigências técnicas previstas em cláusula suspensiva dos Termos de Compromisso, inseridos no Programa de Aceleração do Crescimento - PAC, firmados nos exercícios de 2007, 2008 e 2009. [internet]. Diário Oficial da União; 7 Jan 2010. [acesso em 2017 ago 13]. p. 180. Disponível em: https://is.gd/A6YSE1.

18. Brasil. Ministério das Cidades. Portaria no 312, de 01 de julho de 2011. Estabelecer prazo, até 15 de agosto de 2011, para atendimento das exigências técnicas previstas em cláusula suspensiva dos Termos de Compromisso, inseridos no Programa de Aceleração do Crescimento - PAC, firmados nos exercícios de 2007, 2008 e 2009. [internet]. Diário Oficial da União; 7 abr 2011. [acesso em 2017 ago 13]. p. 129-30 Disponível em: https://is.gd/Obny6N.

19. Brasil. Ministério das Cidades. Portaria no 476, de 07 de outubro de 2011. Estabelece prazo para atendimento das exigências técnicas previstas em cláusula suspensiva dos Termos de Compromisso inseridos no Programa de Aceleração do Crescimento - PAC firmados nos exercícios de 2007, 2008 e 2009 relacionados no anexo desta Portaria. [internet]. Diário Oficial da União; 10 Out 2011. [acesso em 2017 ago 13]. p. 63. Disponível em: https://is.gd/Ki8Z2a.

20. Brasil. Ministério das Cidades. Portaria no 111, de 06 de março de 2012. Estabelece novo prazo para atendimento às exigências técnicas previstas na cláusula suspensiva dos Termos de Compromisso inseridos no Programa de Aceleração do Crescimento - PAC firmados nos exercícios de 2010. [internet]. Diário Oficial da União; 3 Jul 2012. [acesso em 2017 ago 13]. p. 37. Disponível em: https://is.gd/YOaUic.

21. Brasil. Ministério das Cidades. Portaria no 193, de 30 de abril de 2012. Altera os prazos para atendimento de cláusulas suspensivas de operações de Saneamento, Habitação e Encostas selecionadas na segunda fase do Programa de Aceleração do Crescimento - PAC 2. [internet]. Diário Oficial da União; 5 Fev 2012. [acesso em 2017 ago 13]. p. 31. Disponível em: https://is.gd/ jaacm6.

22. Brasil. Ministério das Cidades. Panorama dos Planos Municipais de Saneamento Básico no Brasil [internet]. Secretaria Nacional de Saneamento Ambiental; Jan 2017 [acesso em 2018 fev 2]. Disponível em: https://is.gd/ofaOUV.

23. Brasil. Presidência da República. Relatório de Auditoria Anual de Contas da Secretaria Nacional de Saneamento Ambiental - Ministério das Cidades [internet]. Controladoria-Geral da União. Secretaria Federal de Controle Interno; 25 Jul 2017 [acesso em 2019 fev 1]. Disponível em: https://t.ly/q9n.

24. Jardim MC. A construção social do mercado de trabalho no setor de construção civil nas obras do Programa de Aceleração do Crescimento (PAC): consensos e conflitos. Soc E Estado. 2015; 30(1):165-87.

25. Sader E, Garcia MA, organizadores. A Inflexão do Governo Lula: Política Econômica, Crescimento e Distribuição de Renda. In: Brasil, entre o passado e o futuro [internet]. São Paulo: Fundação Perseu Abramo; Boitempo Editorial; 2010 [acesso em 2018 fev 2]. Disponível em: https://is.gd/GCC81T.

26. Sousa ACA, Costa NR. A Crise do Saneamento Básico no Brasil: uma revisão bibliográfica. Bib 66; 2008.

27. Brasil. Ministério do Desenvolvimento Regional. Secretaria Nacional de Saneamento. SNIS - Série Histórica - Água e Esgotos [internet]. Sistema Nacional 
de Informações sobre Saneamento. [acesso em 2019 fev 13]. Disponível em: http://app4.cidades.gov.br/ serieHistorica/.

28. Arretche M. Federalismo e igualdade territorial: uma contradição em termos? Dados. 2010; 53(3):587-620.

29. Arretche MTS. Políticas sociais no Brasil: descentralização em um Estado federativo. Rev Bras Ciênc Sociais. 1999; 14(40):111-41.

30. Sousa ACA, Costa NR. Ação coletiva e veto em política pública: o caso do saneamento no Brasil (19982002). Ciênc. Saúde Colet. 2011; 16(8):3541-52.

31. Sousa ACA, Costa NR. Incerteza e dissenso: os limites institucionais da política de saneamento brasileira. Rev Adm Pública. 2013; 47(3):587-99.

32. Sousa ACA, Costa NR. Política de saneamento básico no Brasil: discussão de uma trajetória. História Ciênc Saúde-Manguinhos. 2016; 23(3):615-34.

33. Sousa ACA, Barrocas PRG. Privatizar ou não privatizar: eis a questão. A única questão? A reedição da agenda liberal para o saneamento básico no Brasil. Cad. Saúde Pública [internet]. 2017 [acesso em 2019 jul 23]; 33(8). Disponível em: https://t.ly/4jg.

34. Scriptore JS, Toneto Júnior R. A estrutura de provisão dos serviços de saneamento básico no Brasil: uma análise comparativa do desempenho dos provedores públicos e privados. Rev Adm Pública. 2012; 46(6):1479-504.

35. Sarti F, Ultremare F. Padrão de investimento e a estratégia financeira das grandes empresas regionais do setor de Água e Esgoto (A\&E) no Brasil. In: Saneamento como política pública: um olhar a partir dos desafios do SUS [internet]. Rio de Janeiro: Cen- tro de Estudos Estratégicos da Fiocruz; 2018 [acesso em 2019 fev 13]. p. 105-32. (Heller L. Textos para Debate; vol. 2). Disponível em: https://t.ly/nggB.

36. Heller L, Castro JE, organizadores. Política pública e gestão de serviços de saneamento. Edição ampliada. Belo Horizonte: Rio de Janeiro: UFMG; Fiocruz; 2013.

37. Kishimoto S, Petitjean O. Reclaiming public services: how cities and citizens are turning back privatisation [internet]. Amsterdam: Paris: Transnational Institute (TNI); 2017 [acesso em 2018 fev 2]. 236 p. Disponível em: https://www.tni.org/files/publication-downloads/reclaiming_public_services.pdf.

38. Britto AL, Rezende SC. A política pública para os serviços urbanos de abastecimento de água e esgotamento sanitário no Brasil: financeirização, mercantilização e perspectivas de resistência. Cad Metrópole. 2017; 19(39):557-81.

39. Borja PC. Política pública de saneamento básico: uma análise da recente experiência brasileira. Saúde e Soc. 2014; (2):432-47.

40. Lisboa SS, Heller L, Silveira RB. Desafios do planejamento municipal de saneamento básico em municípios de pequeno porte: a percepção dos gestores. Eng Sanit E Ambient. 2013; (4):341-8.

41. Pereira TST, Heller L. Planos municipais de saneamento básico: avaliação de 18 casos brasileiros. Eng Sanit E Ambient. 2015; 20(3):395-404.

Recebido em 24/03/2019

Aprovado em 24/09/2019

Conflito de interesses: inexistente

Suporte financeiro: Fundação de Amparo à Pesquisa do Estado do

Rio de Janeiro (Faperj) 